\title{
Study on the Statistical Methods Used in the Articles of Journal of the Korean Society of Cosmetology (2018)
}

\author{
Chang-Gok Chang ${ }^{1}$, Young-jo Lee L $^{\text {* }}$ \\ ${ }^{1}$ Department of Health Science, Dongduk Women's University, Seoul, Korea \\ ${ }^{2}$ Department of Health and Cosmetics, Dongduk Women's University, Seoul, Korea
}

\author{
*Corresponding author: Young-jo Lee, \\ Department of Health and Cosmetics, \\ Dongduk Women's University, 13-gil, \\ Hwarang-ro, Seongbuk-gu, Seoul 02748 , \\ Korea \\ Tel.: +82 29404482 \\ Fax: +8229404480 \\ Email: leewha88@naver.com
}

Received October 12, 2019

Revised November 19, 2019

Accepted November 28, 2019

Published December 30, 2019

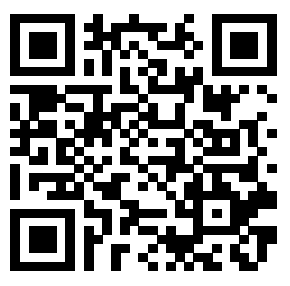

\section{Introduction}

연구재단에 등재된 미용분야 학술지 중에서 1995년에 창간된 한국미용학회지는 첫해 10 편의 연구논문이 실린 이후 2007년부 터 매년 한 해 100 편 이상의 연구논문이 게재되고 있어 미용분야 의 연구가 매우 활발하게 진행되고 있음을 알 수 있다. 이들 연구 논문은 질적연구와 양적연구로 구성되어 있으며, 미용연구 결과 의 과학적 타당성을 입증하기 위하여 통계분석기법을 적용한 양 적연구의 논문이 점점 증가하고 있다. 양적연구의(Park et al., 2019 ; Kwoon \& Heo, 2019)의 경우 연구의 목적과 연구의 설계 및 연구자료의 특성에 따라 적합한 통계분석기법을 적용할 경우 연구 결과의 타당성과 신뢰성을 높이는 결과를 가져오지만 잘못 된 통계분석기법을 적용하거나 통계학적 기술이나 해석상의 오류 를 범할 경우 연구의 결과를 의미 없게 하기도 한다(Yang et al., 2012).

통계적 방법은 자료의 수집, 정리, 요약 및 추정과 추론의 전과
정에 적용되며, 수집된 자료의 특성에 따라 모수적 방법과 비 모 수적 방법으로 구분된다. 통계분석 방법은 자료의 중앙집중성과 산포성으로 요약되는 기술통계와 표본을 통해 모집단의 특성을 언 급하는 추론통계로 구분되며, 연구의 목적과 연구의 설계에 따라 적용되는 통계분석기법의 적용도 달라진다(Ro, 2006; Hong et al., 1994).

통계분석기법을 잘 사용할 경우 연구의 결과가 빛이 날 수 있지 만 잘못 사용할 경우 논문의 가치를 떨어뜨리는 양날의 칼과 같은 성격을 가지고 있기 때문에 연구논문의 작성 전과정에 걸쳐 정확 한 통계적 방법의 적용과 기술 및 해석이 필요하다.

양적 연구의 경우 Rha \& Na (2015)은 한국조리학회지, Ro (2006)은 문헌정보학회지, Kang (2002)은 대한간호학회지, Yang et al. (2012)은 임상약학회지, Kim (1997)은 한국행정학 보, Choi \& Kang (2009)은 대한의학학회지, Kim \& Lee (2014) 는 전산화단층기술학회지, 그리고 Lee \& Lee (1997)은 교육심리 학회지를 분석하여 다양한 학문영역에서 과학적 타당성과 신뢰성 
을 높이기 위해 적용된 통계기법의 적절성과 오류에 대해 분석하 고 올바른 통계기법의 적용방법을 제시하고 있다.

지난 25년 동안 한국미용학회지에 양적 연구논문이 증가함에 따라 연구의 형태와 목적에 부합하는 다양한 형태의 통계분석기법 의 적용이 요구되고 있으나 통계분석기법을 고찰하거나 사용된 통 계기법의 오류를 분석한 논문도 찾아볼 수 없다. 따라서 한국미용 학회지에 게재된 연구논문의 통계적 기법을 분석하고, 사용된 통 계분석기법의 적절성을 평가하고, 통계분석기법의 올바른 사용을 제시할 필요가 있다.

이에 본 연구에서는 미용분야의 양적연구의 과학적 타당도와 신뢰도를 높이기 위해 2018년 1년간 한국미용학회지에 게재된 연 구논문의 연구설계와 적용된 통계분석기법을 고찰하고자 하였으 며, 구체적 목적은 논문에 적용된 연구설계와 통계분석기법을 고 찰하고, 통계기법 기술 시 생략의 문제, 통계용어의 오류, 통계기 법 적용의 오류 및 분석결과 해석의 오류를 고찰하여 최종적으로 연구목적과 연구설계에 적합한 통계분석기법을 제안하고자 하였 다.

\section{Methods}

\section{1. 연구자료}

본 연구는 2018 년에 발간된 한국미용학회지 제1권에서 제 6 권 까지 게재된 학술논문 136 편을 분석에 이용하였다.

\section{2. 연구내용}

본 연구의 내용은 첫째, 논문의 형태와 연구설계를 분석하였고, 둘째, 연구의 목적과 설계에 따라 채택된 통계분석기법의 종류를 분석하였으며, 셋째, 통계 분석결과의 기술과 해석의 적절성에 대 해 평가하였고, 넷째, 연구의 목적과 설계에 적합한 통계기법을 제안하였다.

\section{3. 분류 및 평가기준}

논문의 형태와 설계의 분류기준은 사람을 대상으로 한 설문조 사일 경우 조사연구로 분류하였고 연구의 진행방향에 따라 단면 연구, 전향적 연구 및 후향적 연구로 분류하였다. 연구의 재료나 대상이 물질, 동물 및 사람을 대상으로 실험을 한 경우 실험연구 로 분류하였고, 재료나 대상에 따라 재료, 동물 및 임상연구로 구 분하였다. 한 논문에서 두 가지 연구가 이루어진 경우 복합연구로 분류하였고, 조합에 따라 재료와 임상, 재료와 조사 및 조사와 임 상연구로 구분하였다. 새로운 디자인의 개발이나 색채 개발 등 수 치화되지 않은 연구를 질적 연구로 구분하였고, 동일한 주제를 다 룬 기존의 다양한 연구결과를 통계적 분석을 통해 새로운 결과를 유도하는 연구를 고찰연구로 분류하였다.
통계분석방법의 분류기준은 연구목적을 달성하기 위해 채택된 주요 분석기법을 중심으로 분류하였으며, 주요 분석기법을 수행 했을 때 부가적으로 생성되어 제시된 통계기법은 계산하지 않았 다. 통계기법 사용의 적절성 평가기준은 다음과 같다.

첫째, 필요한 기술의 생략

둘째, 통계용어 사용의 적절성

셋째, 연구자료와 연구목적에 적합한 통계기법의 적용

넷째, $p$-value의 올바른 기술과 해석

다섯째, 분석결과에 대한 올바른 해석

\section{4. 통계분석방법}

모든 자료는 엑셀 파일로 저장하였고, 연구의 형태와 통계기법 의 종류는 빈도와 퍼센트와 같은 기술통계를 계산하였다.

\section{Results and Discussion}

\section{1. 연구논문의 형태}

2018년 한국미용학회지에 게재된 논문은 총 137 편이었으며 연 구의 형태는 5 가지로 조사연구가 73 편(53.3\%)으로 과반을 차지 하였으며, 실험연구가 29편(21.2\%), 조사와 실험연구를 병행한 복합연구가 14 편(10.2\%), 질적연구가 12 편(8.8\%) 및 고찰연구가 9편(6.6\%) 순이었다.

연구의 설계는 조사연구에서는 단면연구설계 즉, 현시점에 서 한꺼번에 표본을 추출하여 정보를 수집한 관찰연구가 72 편 (98.6\%)이었으며, 현시점에서 위험에 노출된 집단과 노출되지 않 은 집단을 표본 추출하여 미래에 나타난 결과를 비교하는 전향 적 연구설계는 단 1 편(1.4\%)에 불과하였다. 실험연구는 물리적 재료를 이용한 실험이 22 편(75.9\%), 동물을 대상으로 실시한 실 험은 1 편(3.4\%) 그리고 사람을 대상으로 실시한 임상시험은 6 편 (20.7\%) 이었다. 한 연구에서 두 가지 다른 연구설계를 적용한 복합연구는 재료를 만들고 이를 임상에 적용한 실험연구는 7편 (50.0\%), 재료를 이용하여 제품을 만들거나 디자인을 하고 이를 사람을 대상으로 설문조사를 실시한 연구는 3 편(21.4\%), 그리고 임상시험을 하고 만족도를 조사한 연구는 4 편 $(10.2 \%)$ 이었다. 디 자인을 분류하거나 개발한 질적연구는 12 편(8.8\%)이었고, 여러 논문을 고찰한 연구는 9 편(6.6\%)으로 나타나 매우 다양한 형태의 연구와 연구설계를 적용하고 Table 1 에 있음을 알 수 있다.

양적연구 논문이 $90 \%$ 이상 차지하는 결과는 조리학회지에 게 재된 논문에 사용된 통계적 기법을 분석한 Rha \& NA (2015)의 연구와 일치한다.

\section{2. 사용된 통계기법의 종류}

논문에 사용된 통계는 한 논문에서 여러 가지의 통계기법을 적 
용하였다. 평균치의 검정은 81 회( $35.1 \%)$, 변수 간의 상관성 검정 은 42 회(18.2\%), 예측이나 변수 간의 경로를 분석한 검정은 46 회 (19.9\%), 분류를 위한 기법은 60 회(26.0\%), 그리고 메타분석은 2 회 $(0.9 \%)$ 를 사용하였다.

평균치의 비교는 모수적 방법으로 분산분석을 40 회(49.4\%)로 가장 많이 사용하였고, 다음이 독립 $t$-test 31 회(38.3\%), 짝표본 $t$-test 7회(8.6\%), 비 모수적 방법으로 Mann-Whitney U test 2 회(2.5\%), Wilcoxon signed-rank test 1회(1.2\%) 사용하였다.

상관성 검정은 연속변수의 경우 두 변수의 상관의 정도를 파악 하기 위해 Pearson 상관분석을 22 회(52.4회), 범주형 자료인 경 우 두 변수의 상관성 유무를 확인하기 위해 카이제곱검정 17 회 (40.5\%), Fisher's exact test를 3회(7.1\%) 사용하였다.

예측과 구조분석에서 회귀분석은 42 회(18.2\%), 변수들 간의 구 조를 파악하기 위한 구조방정식은 2 회 $(4.0 \%)$, 변수들 간의 경로 계수를 구한 경로분석은 3 회 $(7.0 \%)$ 사용하였다.

변수들 간에 잠재된 공통요인을 찾아내는 요인분석은 55 회 (91.7\%), 유형의 분류를 위한 $\mathrm{K}$-평균 군집분석은 5 회(8.3\%) 사 용하였다.

동일 주제의 상반된 다양한 연구결과를 재분석하여 종합한 메 타분석은 출판편의를 위한 Trim-and-Fill 및 안전성계수 검증과 Cohen의 효과크기의 $95 \%$ 신뢰구간 검증을 Table 2 에 사용하였 다.

\section{3. 사용된 통계기법의 오류}

사용된 통계기법의 오류는 Table 3에 정리한 바와 같이 생략의 문제, 부정확한 통계용어의 사용, 부정확한 통계기법의 사용, 분 석 결과 해석의 오류였다.

1) 생략의 문제

첫째, 연구방법의 분석기법 기술에서 통계기법의 생략 둘째, 연구결과의 기술에서 분석결과표의 생략

셋째, 사후검정 후 각각의 평균치의 비교를 위한 표시 생략

넷째, 연구 결과의 유의성 언급에서 검정통계량 또는 $p$-value 생략

즉, 연구결과에 나타난 통계기법을 연구방법의 분석기법에 기 술하지 않아 자료분석에 어떤 통계기법을 사용하였는지를 알 수 없었고, 자료분석에 사용된 통계분석의 결과표를 제시하지 않아 자료가 올바로 분석되었는지 알 수 없으며, 또한 표와 함께 제시 되는 다양한 통계정보가 제시되지 않아 연구결과의 타당성을 확인 할 수 없는 경우가 있었다. 그리고 분산분석 결과 유의한 차이가 있을 경우 사후검정을 하는데 검정결과 그룹별 평균값에 $\mathrm{a}, \mathrm{b}, \mathrm{c}$, $\mathrm{d}$ 를 표시하여 유의한 차이를 알 수 있도록 하지 않았고, 연구결과 의 유의성을 언급하면서 사용된 검정통계량과 그에 따른 $p$ 값을 생 략하였다.

이와 같이 생략의 문제는 Rha \& $\mathrm{Na}$ (2015), Yang et al. (2012)의 연구에서도 동일하게 지적하였다.

Table 1. Research type and study design employed in the articles published in the JKSC (2018)

\begin{tabular}{llc}
\hline Research type & Study design & Frequency (\%) \\
Survey & Cross-sectional study & $72(98.6)$ \\
& Prospective study & $1(1.4)$ \\
& Sub total & $73(53.3)$ \\
& Material & $22(75.9)$ \\
Experiment & Animal & $1(3.4)$ \\
& Human & $6(20.7)$ \\
Sub total & $29(21.2)$ \\
Mixed & Material+Human & $7(50.0)$ \\
Total & Material+Survey & $3(21.4)$ \\
\hline Survey+Human & Sub total & $4(28.6)$ \\
\hline
\end{tabular}

JKSC, Journal of the Korean Society of Cosmetology. 
2) 부정확한 용어의 사용

첫째, 기술통계분석, 빈도분석

둘째, 평균표준오차

셋째, 상관관계분석

즉, 빈도분석은 명목척도로 측정된 범주형 자료의 빈도를 이용 하여 카이제곱과 같은 통계적 검정을 통하여 적합성, 동질성 또는 상관성을 분석하는 것임에도 불구하고 연구대상의 특성을 요약하 면서 기술통계분석, 빈도분석 또는 두 가지 용어를 한꺼번에 사용 하였다.

표본을 이용하여 모집단을 추정하거나 가설검정을 하지 않고 단순히 수집된 자료를 요약할 경우는 표준편차를 사용해야 함에 도 불구하고 표준오차를 사용하였고, 두 변수의 상관관계를 분석 할 때의 올바른 통계학적 용어는 상관분석(correlation analysis) 이다.

이와 같이 의학연구논문의 통계적 기법의 활용을 분석한 Choi \& Kang (2009)의 논문에서도 부정확한 명칭의 사용을 지적하고 올바른 통계용어의 사용을 권장하였다.

3) 부정확한 분석기법의 적용
첫째, 세 가지의 평균을 검정하면서 $t$-test 적용

둘째, 720 개의 자료를 이용하여 그룹 간 평균치를 비교하면서 비모수적 방법인 Kruskal-Wallis test를 사용

셋째, 4 개의 군을 4 주간 매주 측정치를 매주 비교하면서 단순 $\mathrm{ANOVA}$ 검정 적용

세 가지 이상의 평균을 검정할 때는 제 1 종 오류의 증가 때문 에 분산분석(ANOVA)를 해야 하고, 표본이 많은(대수) 경우 중심 극한정리에 의거 분산분석을 실시하여야 하며, 군간 및 주별 측 정치의 변화와 유의성을 검정하기 위해서는 반복측정분산분석 (repeated measures of ANOVA)을 실시해야 한다.

Yang et al. (2012), Yu et al. (2003) 논문에서도 이와 같이 부 정확한 분석기법의 사용을 지적하였다.

4) 분석결과 해석의 오류

첫째, $p$-value에 대한 해석 오류

둘째, 분석결과의 과도한 해석

분석결과 $p<0.05$ 임에도 불구하고 "유의한 차이가 없다."라고 기술하거나, 회귀분석 결과 $R^{2}=0.068, R^{2}=0.018$ 과 같이 종속변 수에 대한 독립변수의 설명력이 매우 낮음에도 불구하고 독립변수

Table 2. Statistical techniques used in the articles published in the JKSC (2018)

\begin{tabular}{|c|c|c|}
\hline Purpose & Types of Methods & Frequency (\%) \\
\hline \multirow{6}{*}{ Comparison of mean } & $t$-test & $31(38.3)$ \\
\hline & Paired $t$-test & $7(8.6)$ \\
\hline & ANOVA & $40(49.4)$ \\
\hline & Mann-Whitney U test & $2(2.5)$ \\
\hline & Wilcoxon signed-rank test & $1(1.2)$ \\
\hline & Sub total & $81(35.1)$ \\
\hline \multirow{4}{*}{ Correlation } & Correlation analysis & $22(52.4)$ \\
\hline & Chi-square test & $17(40.5)$ \\
\hline & Fisher's exact test & $3(7.1)$ \\
\hline & Sub total & $42(18.2)$ \\
\hline \multirow{4}{*}{ Prediction } & Regression analysis & $41(89.0)$ \\
\hline & Structural equation model & $2(4.0)$ \\
\hline & Path analysis & $3(7.0)$ \\
\hline & Sub total & $46(19.9)$ \\
\hline \multirow{3}{*}{ Classification } & Factor analysis & $55(91.7)$ \\
\hline & Cluster analysis & $5(8.3)$ \\
\hline & Sub total & $60(26.0)$ \\
\hline Others & Meta-analysis & $2(0.9)$ \\
\hline Total & & $231(100.0)$ \\
\hline
\end{tabular}

JKSC, Journal of the Korean Society of Cosmetology. 
가 종속변수의 예측에 매우 중요한 요인이라고 Table 3 에해석하 였다. 결과 해석의 오류는 Yang et al. (2012)의 논문에서도 지적 하였다.

\section{4. 통계기법의 올바른 사용법}

1) 자료의 기술

수집된 자료의 기술을 위해서는 수집된 자료의 특성에 따라 자 료의 척도에 따라 명목척도일 경우 빈도와 \%, 양적 척도일 경우 중앙집중성(평균, 중앙치)과 산포성(표준편차, 사분위편차)로 기 술하고 이 때 통계용어는 기술통계라 쓰고, 표에는 측정단위를 기 술한다.

\section{2) 평균치의 검정}

실험이나 조사를 통해 수집된 자료의 경우 평균치를 검정하는 경우가 많다.

첫째, 수집된 자료가 정규분포를 만족하고 독립된 두 집단의 평 균을 비교할 경우 $t$-test를 하고, 비교하는 자료가 짝이거나 자신
의 전후 측정값 일 경우 대응표본(paired) $t$-test를 한다.

둘째, 수집된 자료가 정규분포를 만족하고 세 집단 이상의 평균 치를 비교할 경우 분산분석(ANOVA)를 통해 $F$-test를 한다. 집단 별로 연구대상을 일정 시간간격에 따라 3 회 이상 반복 측정하고, 매측정치의 평균치의 차이를 검정하고자 할 경우 반복측정분산분 석(repeated measures of ANOVA)을 실시하여 $F$-test를 하고 유의한 경우 사후검정을 실시하여 시간간격별 차이를 검정한다.

셋째, 수집된 자료가 서열척도인 경우와 표본수가 적고 정규 분포를 하지 않은 경우 두 집단 간의 비교는 맨-휘트니 유 검정 (Mann-Whitney U test), 세 집단 간의 비교는 크루스칼-왈리스 검정(Kruskal-Wallis test)과 같은 비모수적 방법을 적용한다.

\section{3) 상관관계분석}

변수 간의 상관성을 분석하기 위해 상관성의 정도나 상관성의 유무를 검정하는 경우가 많다.

첫째, 두 변수의 상관성의 정도는 측정치가 양적변수일 경우 피어슨 상관분석(Pearson correlation analysis)을 사용하고, 표

Table 3. Errors in statistical methods used in the articles published in the JKSC (2018)

\begin{tabular}{|c|c|c|}
\hline Type of error & \multicolumn{2}{|c|}{ Content of the error } \\
\hline Omission & $\begin{array}{l}\text { 1) Statistical analysis } \\
\text { 2) Omission of outcome table } \\
\text { 3) Test statistics } \\
\text { 4) } p \text {-value }\end{array}$ & $\begin{array}{l}\text {-The statistical techniques used in the article } \\
\text { should be described in the research method. } \\
\text {-Statistical outcome table should be } \\
\text { presented to give more information. } \\
\text {-Test statistic and } p \text {-value should be } \\
\text { presented when mentioning that the result } \\
\text { was significant. }\end{array}$ \\
\hline Incorrect term & $\begin{array}{l}\text { 1) Frequency analysis } \\
\text { 2) Standard error }\end{array}$ & $\begin{array}{l}\text {-Frequency analysis should be used in case of } \\
\text { analyzing the contingency table. } \\
\text {-Standard deviation should be used in case } \\
\text { of describing the characteristic of study } \\
\text { subjects. }\end{array}$ \\
\hline Wrong techniques & $\begin{array}{l}\text { 1) } t \text {-test } \\
\text { 2) F-test } \\
\text { 3) Kruskal-Wallis test } \\
\text { 4) ANOVA }\end{array}$ & $\begin{array}{l}\text { - } t \text {-test should be used in case of comparing } \\
\text { means less than } 2 \text { samples. } \\
\text {-Kruskal-Wallis test should be used in case } \\
\text { the sample size is }<30 \text { and the sample is not } \\
\text { normally distributed. } \\
\text {-ANOVA should be used in case of comparing } \\
3 \text { and more means. }\end{array}$ \\
\hline $\begin{array}{l}\text { Wrong } \\
\text { interpretation }\end{array}$ & $\begin{array}{l}\text { 1) } p \text {-value } \\
\text { 2) Over interpretation }\end{array}$ & $\begin{array}{l}-p<0.05 \text { means that null hypothesis is } \\
\text { rejected and the result is statistically } \\
\text { significant. } \\
\text {-Independent variable is not predictive } \\
\text { estimating the dependent variable in case of } \\
\mathrm{R}^{2}=0.018 \text {. }\end{array}$ \\
\hline
\end{tabular}

JKSC, Journal of the Korean Society of Cosmetology. 
본수가 작은 양적변수나 서열척도인 경우 비모수적 방법인 스 피어만이나 켄달의 순위상관계수(Spearman/Kendall's rank correlation coefficient)를 구한다.

둘째, 두 변수의 상관성 여부는 명목척도 측정된 자료는 분할표 를 작성하여 카이제곱검정 $\left(\chi^{2}-\right.$ test)과 같은 비모수적 방법을 사 용하여 빈도분석을 한다. 이 때 분할표가 $2 \times 2$ 이면서 기대빈도가 5 이하인 칸(cell)이 전체의 $20 \%$ 이상인 경우 피셔의 정확확률검 정(Fisher's exact test)을 실시하여 두 변수의 상관성 유무를 판 단한다.

셋째, 층화 또는 대응자료의 분할표에서 상관성 정도를 분석 하고자 할 때는 코크란-맨텔-핸 통계량(Cochran-MantelHaenszel statistics)을 구한다.

\section{4) 설명 및 예측}

독립변수와 종속변수의 관계를 설정하여 종속변수를 설명하거 나 예측하고자 할 때 사용한다.

첫째, 독립변수와 종속변수가 모두 연속변수이고 가정을 만족 할 때 회귀분석을 실시한다.

둘째, 종속변수가 연속형이 아니고 범주형 자료인 경우 일반선 형모형의 가정을 만족시킬 수 없기 때문에 종속변수를 적절한 함 수로 변화시킨 $\mathrm{f}(\mathrm{x})$ 와 독립변수의 선형결합으로 모형화한 일반 화선형모형(generalized regression analysis)을 적용한다. 일 반화선형모형에는 로지스틱회귀분석, 콕스비례위험모형(Cox proportional hazards model) 등이 있다.

\section{5) 변수의 축약}

변수들 간의 상관관계를 이용하여 상관성이 높은 변수들끼리 묶어 변수를 줄이는 방법으로 주성분분석과 요인분석 및 정준상관 분석이 있으며, 여기서는 요인분석과 주성분분석만 제시한다.

첫째, 설문분석에서 리커트(Likert) 척도로 조사된 문항들을 서 로 관련이 높은 문항끼리 그룹화하여 새로운 요인을 도출하는 요 인분석을 실시한다. 이때 신뢰성 계수 Cronbach $\alpha$ 는 선택된 문항 에 대한 값을 구해야 한다.

둘째, 3 개 이상의 원변수를 1-2개의 축약한 새로운 변수 즉, 주성분으로 줄이고, 새로 만들어진 주성분 변수에 대한 개념을 정 의하고자 할 때 주성분분석을 실시한다.

\section{6) 개체의 분류}

개체들의 특성을 측정한 변수들의 상관관계를 이용하여 유사한 개체끼리 분류하는 방법으로 군집분석과 판별분석이 있다.

첫째, 군집분석은 측정변수들을 이용하여 개체 간 거리(유사성) 을 구하여 개체를 분류할 때 사용한다.

둘째, 판별분석은 측정변수들의 선형결합형태의 판별식을 구
하고 이를 이용하여 새로운 개체를 분류할 때 사용한다(Kwon \& Choe, 2013).

\section{Conclusion}

본 연구는 2018년에 발간된 한국미용학회지에 게재된 136편 의 논문을 이용하여 논문의 형태와 연구설계, 사용된 통계분석기 법을 분석하였고, 통계기법 적용 오류 및 해석의 평가를 통해 올 바른 통계기법의 사용법을 제시하였다. 통계기법 사용 적절성 의 평가는 첫째, 필요한 기술의 생략 둘째, 통계용어 사용의 적절 성 셋째, 연구자료와 연구목적에 적합한 통계기법의 적용 넷째, $p$-value의 올바른 기술과 해석 및 다섯째, 분석결과에 대한 올바 른 해석을 기준으로 하였다.

연구결과 논문의 형식은 조사연구가 $53.3 \%$, 실험연구가 $21.2 \%$ 였고, 사용된 통계기법은 평균치의 검정 $(35.1 \%)$ 과 요인분석 (23.8\%)이 $58.9 \%$ 였다. 사용된 통계기법의 오류는 첫째, 통계분 석기법과 검정 통계량 및 $p$-value의 생략이 가장 많았다. 둘째, 빈도분석, 상관관계분석, 표준오차와 같이 용어를 잘못 사용한 것 으로 나타났다. 셋째, 일부 논문에서 $t$-test, ANOVA, KruskalWallis test와 같은 통계기법을 잘못 적용하였다. 넷째, 해석의 오 류는 $p$-value의 잘못 해석과 분석결과의 과도한 해석이었다.

결론적으로 연구논문의 타당성과 신뢰성을 높이기 위해서는 양 적연구에 있어 통계기법을 정확하게 사용할 필요가 있다.

본 연구는 1 년간의 연구논문의 분석으로 제한되어 있기 때문에 연구의 결과를 일반화할 수 없다.

\section{Author's contribution}

CGC and YJL contributed equally to this work. CGC and YJL designed, collected 200 Articles of the Korean Society of Cosmetology. CGC oversaw the project, analyzed data. YJL wrote the manuscript and revised the necessary part of the paper. All authors read and approved the final manuscript.

\section{Author details}

Chang-Gok Chang (Professor), Department of Health Science, Dongduk Women's University, 60, Hwarang-ro 13-gil, Seongbuk-gu, Seoul 02748, Korea; Young-jo Lee (Graduate student), Department of Health and Cosmetics, Dongduk Women's University, 13-gil, Hwarang-ro, Seongbuk-gu, Seoul 02748, Korea. 


\section{References}

Choi YW, Kang KH. On statistical methods used in medical research. Journal of the Korean Data \& Information Science Society, 20: 357-367, 2009.

Hong ES, Song YS, Lee KK. Cytopathic effect and cell viability on the HaCaT cell line of para-phenylenediamine of hair dye ingredients. Journal of the Korean Society of Cosmetology, 24: 1306-1315, 2009.

Kang HC. Last 3 Years (1999-2001) Journal of Nursing for the use of statistical techniques for analysis. Journal of Korean Academy of Nursing, 32: 929-935, 2002.

Kwon JG, Choe WS. Content analysis on suitability by research phase that inflect statistical method of design science research papers. Brand Design Association of Korea 11:121-138, 2013.

Kim T. A review of statistical methods in public policy studies. Korean Public Administration Review, 31: 19-35, 1997.

Kim SH, Lee MH. Evaluation of statistical analysis of radiologist's journal: focus on Journal of Korean Society of Computer Tomographic Technology. The Society of Digital Policy \& management, 12: 275-28, 2014.

Kwoon TI, Heo Hs. Appearance satisfaction and self-esteem according to the actual situation of eyelash beauty. Asian Journal of Beauty and Cosmetology, 17: 295-306, 2019.
Lee SD, Lee HW. Analysis of statistic techniques used in Journal of Educational Psychology (1984-1993). Korean Journal of Education Psychology, 11: 149-164, 1997.

Park JE, Yoo AJ, Park EJ. Human resource management according to the characteristics of beauty service workers. Asian Journal of Beauty and Cosmetology, 17: 331-343, 2019.

Rha YA, Na TK. Analysis of the statistical methods used in scientific research published in The Korean Journal of Culinary Research. Culinary Science and Hospitality Research, 21: 49-62, 2015.

Ro JS. A critical review of the use of inferential statistics in library and information science research in Korea. Journal of the Korean Library and Information Science Society, 40: 217-247, 2006.

Yang SH, Lee TR, Lee SH, Rhew KY. Analysis on the statistical methods and errors in articles of Korean Journal of Clinical Pharmacy. Journal of The Korea Society of Health Informatics and Statistics, 37: 1-11, 2012.

Yu TY, Jin YH, Jeong TO, Lee JB. Statistical methods in the articles in the Journal of the Korean Society of Emergency Medicine published from 1998 to 2002. Journal of The Korean Society of Emergency Medicine, 14: 475-480, 2003. 


\section{국문초록}

\section{한국미용학회지(2018년)에 게재된 논문의 통계분석기법 고찰}

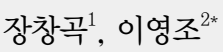

${ }^{1}$ 동덕여자대학교 보건관리학과, 서울, 한국

${ }^{2}$ 동덕여자대학교 보건향장학과, 서울, 한국

목적: 본 연구의 목적은 2018년 한국미용학회지에 게재된 논문의 통계적 방법을 고찰하기 위한 것이다. 방법: 2018년 한국미용학 회지에 게재된 총 136 개의 논문을 사전 정의된 기준에 따라 연구 유형, 통계 기법, 통계적 오류를 고찰하고 빈도와 퍼센트로 제시하 였다. 결과: 총 $74.5 \%$ 의 논문이 설문조사와 실험 연구였고, 총 14 가지 종류의 통계기법을 사용하였고, $t$-test, 분산분석 및 요인분 석이 $56.3 \%$ 사용되었다. 논문에 사용된 통계기법의 오류는 통계용어와 사용한 통계기법의 생략과 잘못된 용어와 기법의 적용 및 분 석결과의 해석 오류였다. 결론: 연구의 타당성과 신뢰성을 높이기 위해 통계적 방법을 정확하게 사용할 필요가 있다.

핵심어: 한국미용학회지, 연구유형, 통계기법, 통계용어, 통계적 오류

\section{참고문헌}

강현철. 최근 3년간(1999-2001)대한간호학회지의 통계기법 활용에 대한분석. 한국간호과학학회지, 32: 929-935, 2002.

권재경, 최원수. 통계학적 기법을 활용한 디자인학 연구논문의 연구단계별 적절성에 관한 내용분석 연구. 브랜드디자인학 연구, 11: 121-138, 2013.

권태일, 허혜순. 속눈썹 미용실태에 따른 외모만족도와 자아존중감. 아시아뷰티화장품학술지, 17: 295-306. 2019.

김상현, 이미화. 방사선사 학술지에 게재된 통계방법 분석: 대한전산화 단층기술학회지 중심으로. 전산화단층기술학회지, 12: 275-282, 2014.

김태일. 행정학분야 논문에 사용된 통계기법들의 분석. 한국행정학보, 31: 19-35. 1997.

나영아, 나태균. 한국조리학회지에 게재된 학술적 연구의 통계적 기법분석. 한국조리학회지, 21: 49-62, 2015.

노정순. 추론통계를 사용한 문헌정보학 연구에서 데이터 수집과 분석에 관한 비평적 고찰. 한국문헌정보학회지, $40: 217-$ 247, 2006.

박정은, 유애진, 박은준. 미용서비스업 종사자의 특성에 따른 인적자원관리연구. 아시아뷰티화장품학술지, 17: 331-343, 2019.

양성희, 이태림, 이숙향, 유기연. 한국임상약학회지에 게재된 논문의 통계분석기법에 대한 고찰. 한국보건정보통계학회지,

37: 1-11, 2012.

유태영, 진영호, 정태오, 이재백. 대한응급의학회지에 게재된 논문의 통계기법에 관한 고찰. 대한응급의학회지, $14: 475-$ 480, 2003.

이신동, 이해범. Journal of Educational Psychology에서 사용된 통계기법의 분석(1984-1993). 교육심리연구, 11: 149-164, 1997.

최기웅, 강기훈. 의학연구논문에서 통계적 기법의 활용. 한국데이터정보과학회지, 20: 357-367, 2009.

홍은설, 송연숙, 이근광. para-Phenylenediamine처리에 따른 $\mathrm{HaCaT}$ 세포주기의 세포변성효과 및 생존율. 한국미용학 회지, 24: 1306-1315, 2018. 


\section{中文摘要}

\section{8年韩国美容学会杂志文章中使用的统计方法}

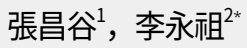

${ }^{1}$ 同德女子大学保健管理学科, 首尔, 韩国

1同德女子大学保健香妆学科，首尔，韩国

目的: 本研究的目的是回顾在《韩国美容学会杂志》上发表的文章中使用的统计方法。方法: 分析2018年发表的 136篇文章。使用诸如频率和百分比之类的描述性统计数据, 我们根据预定义的标准回顾了各自的研究类型, 统 计技术和统计误差。结果: $74.5 \%$ 的提交文章使用问卷调查和实验研究。使用了14种不同类型的统计技术, 其中 56.3\%涉及t检验, 方差分析（ANOVA）和因素分析。在所使用的统计方法中识别出的错误包括遗漏, 不正确的 统计术语用法, 不正确的统计技术用法以及在统计学上解释相应结果时的错误。结论: 有必要促进正确和适当地 使用统计方法, 以提高各自研究的有效性和可靠性。

关键词: 韩国美容学会杂志, 研究类型, 统计技术，统计术语，统计误差 
